\title{
A INFÂNCIA A PARTIR DOS DIZERES E FAZERES DAS CRIANÇAS NA ESCOLA: ENCONTROS SILENCIOSOS E POTENTES
}

\author{
Nádia Priscila de Lima Carvalho ${ }^{\mathrm{i}}$ \\ Fernanda Maria Santos Albuquerque ${ }^{\mathrm{ii}}$ \\ Conceição Gislane Nóbrega Lima de Salles ${ }^{\text {iii }}$
}

\begin{abstract}
RESUMO: O presente artigo é um fragmento de uma pesquisa que visou compreender como as crianças vivenciam o processo de transição da Pré-escola para o $1^{\circ}$ ano do Ensino Fundamental. Aqui, de modo específico, abordamos os dizeres e os fazeres das crianças no ambiente escolar que retratam a transgressão de regras como forma silenciosa e potente de criação. $O$ mesmo busca dialogar com a infância a partir de outros modos de entendê-la, ancorado nas discussões provenientes do campo da filosofia, considerando a infância como experiência. Os dizeres e fazeres das crianças e suas experiências engendram outros vieses que não complementam o posto, mas o reconfigura sob outras dimensões, resistentes e ousadas. Eles evocam as possibilidades que as crianças trazem consigo para nossas instituições escolares.
\end{abstract}

Palavras-chave: criança; infância; experiência; escola; transgressões.

\section{CHILDHOOD FROM CHILDREN'S SAYING AND DOING AT SCHOOL: SILENT AND POTENT MEETINGS}

\begin{abstract}
This article is a fragment of a research that shows how children experience the process of transition from preschool to elementary school. Here, specifically, we address the sayings and what children do in the school environment that portray rule transgression as a silent form and potential for creation. It seeks to dialogue with childhood from other modes of entry, anchored in the discussions Results from the field of philosophy, considering childhood as an experience. The sayings and doings of children and their experiences engender others that do not complement the post, but reconfigure into other resilient and bold dimensions. They evoke the possibilities children bring with them to our school institutions.
\end{abstract}

Keywords: child; childhood; experience; school; transgressions.

A presença da criança na escola, sua entrada na instituição de ensino e a mudança de escolaridade são elementos importantes que trazem para o centro do debate na área de educação aquilo que é específico aos sujeitos a quem a educação está destinada, considerando, desse modo, a infância e a natureza da criança. O Ensino Fundamental, principalmente em seus anos iniciais, necessita vislumbrar os sujeitos de seu contexto e todo seu histórico de direitos e necessidades, colocando a criança como elemento norteador do trabalho na escola. Para Sonia (c) (i) (2)

2020 Bargas; Ayoub; Assaritti, Scarazzatto, Assis. Este é um artigo de acesso aberto distribuído sob os termos da Licença Creative Commons Atribuição Não ComercialCompartilha Igual (CC BY-NC-4.0), que permite uso, distribuição e reprodução para fins não comerciais, com a citação dos autores e da fonte original e sob a mesma licença 
Kramer (2007), isso significa que as crianças devem ser atendidas nas suas necessidades (a de aprender e a de brincar) e que, tanto na Educação Infantil quanto no Ensino Fundamental, sejamos capazes de ver, entender e lidar com as crianças como crianças.

O que assevera a lógica do aluno e, muitas vezes, limita a presença de certas especificidades vividas pelas crianças e suas infâncias no Ensino Fundamental é o modo como são apresentadas as novas experiências às crianças. O que se pode observar é que a dimensão da instrução acaba sendo mais valorizada que as demais dimensões presentes na escola, que a infância parece ser, cada vez mais, deixada à margem da escola. Com isso, não queremos tratar da escolarização da criança de modo negativo, visto que, antes de mais nada, a mesma é configurada como um direito que deve ser garantido a cada criança, mas, queremos atentar para o não esquecimento da mesma como sujeito que também possui outras necessidades.

Concordamos com Moreno e Paschoal (2009) quando tratam do Ensino Fundamental de Nove Anos. As autoras afirmam que a ideia não é unificar o conteúdo da Pré-escola com o conteúdo do primeiro ano, compondo uma nova estrutura curricular, mas sim elaborar uma proposta adequada às crianças, de maneira que a infância continue fazendo parte da vida das mesmas. A continuação da abordagem da infância no $1^{\circ}$ ano não quer dizer que os elementos da Pré-escola devam ser enfatizados, mas que a brincadeira, a ludicidade e a construção de um ambiente motivador devam ser aprimorados como forma de afirmação dessa infância no ambiente escolar.

Assim, para falar de uma educação que torne a criança como centro de seu trabalho, considerando as especificidades dessa faixa etária, é importante falar um pouco mais da infância e de como ela instiga-nos na busca por outros caminhos, por outras perspectivas, por trazer para a cena um olhar potente sobre a educação das crianças.

Nesse sentido, é importante considerar que as concepções que nos auxiliam a pensar a infância são diversas. São caminhos que buscam retratá-la e que, ao mesmo tempo, levam a novos caminhos cheios de significados e questionamentos. No que diz respeito ao termo infância, seu legado histórico encontra-se inclinado a uma perspectiva biologicista do desenvolvimento humano que define perímetros etários da fase criança/adulto, na qual nos é apresentada a noção de quando se é criança e quando se deixa essa condição, ao ser adolescente e, posteriormente, adulto. 
Muitos são os modos de pensar a infância, cada qual com sua importância e modos outros de entendimento, que não se restringem ao que está posto, ao que pensamos saber, mas que se relacionam àquilo que habita em nosso pensamento, que não permitem definições, enclausuramentos. Este último representa nosso entender a respeito da infância, infância não perimetral, mas constituída do nosso não saber, parte do desconhecido, do algo a mais, que foge a qualquer entendimento totalizador.

Não obstante, destacamos os estudos pioneiros de Ariès (1983), quando o mesmo atrela a infância, o surgimento do sentimento de infância, ao nascimento de uma nova configuração familiar a partir da idade moderna. Conforme Ariès (1983), depois de mitigada a dependência direta das crianças em relação aos adultos, ou seja, após os primeiros anos de vida, ambos costumavam dividir a participação social, as mesmas práticas e os mesmos conhecimentos. No entanto, para o autor, as mudanças contextuais modernas não só provocaram a diferenciação entre as crianças e as pessoas adultas, como também denotou maior importância à infância.

Nesta direção, "Não apenas o futuro da criança, mas também sua simples presença e existência eram dignas de preocupação - a criança havia assumido um lugar central dentro da família" (ARIÈS, 1983, p. 7). Para Ariès (1983), o sentimento de infância surgiu junto com a modernidade que, diferentemente de outras épocas, tornou visível uma nova relação com a criança como partícipe do conjunto familiar. Junto a este sentimento está o cuidado da família com a vida da criança, seu bem-estar e sua inserção na sociedade.

Postman (1999) também faz algumas considerações em torno do aparecimento da infância em meio às vivências sociais, atrelando-o às condições de comunicação. Para este autor, o modo de comunicação prevalecente na Idade Média foi a oralidade, no qual não se evidenciava a distinção entre a participação da criança e a participação do adulto em sociedade. Assim, conforme este autor, apenas com a invenção da prensa tipográfica e a decorrente criação de um novo mundo simbólico evidenciou-se uma lacuna entre os indivíduos, especialmente entre adultos e crianças.

Segundo Postman (1999), a leitura passou a ser necessária à efetiva participação social e considerada uma condição da pessoa adulta. Desse modo, a alfabetização foi instituída como critério da vida adulta, a infância como um tempo de preparação para a mesma e a educação como via para as vivências sociais.

Revista Interinstitucional Artes de Educar. Rio de Janeiro, V. 6, N.2-pág. 676-691 maio-agosto de 2020: "Bebês e crianças: cultura, linguagem e políticas"

DOI: 10.12957/riae.2020.45962 
Consideramos que essa infância, definida e mapeada historicamente por etapas, por idades e por fases da vida, apoiadas na proteção e no cuidado por parte dos adultos, bem como na inclusão e exclusão em determinadas práticas sociais, é a que mais conhecemos. $\mathrm{O}$ surgimento da infância, culturalmente enraizado, contempla a mesma em meio a determinações e dependências, sobretudo no âmbito educacional. Segundo Oliveira (2008), neste âmbito, podemos destacar desde as considerações modernas de Rosseau (1592-1670) até as contribuições de Montessori (1870-1952) para a educação das crianças no século XX.

Oliveira (2008) faz-nos refletir acerca das bases para um sistema de ensino mais centrado na criança junto a Rosseau e seu posicionamento contra preconceitos e autoritarismos que ferem a liberdade de uma suposta natureza infantil, sua valorização da infância através de suas experiências e contatos com a realidade. A autora provoca-nos também com a contraproposta de Montessori, que não coloca a natureza como adequada para o desenvolvimento da criança, mas propõe um contexto estimulante para o mesmo, encarregando o educador da preparação do ambiente e da observação das iniciativas infantis.

Assim sendo e tendo em vista todo o contexto criado ao longo de tempos para explicar a infância, sob a condição de sua existência, visibilidade e educação, seria correto afirmar que já estamos abastecidos de saberes e pensamentos que se somam no entendimento da mesma e sua possível elucidação. Porém, quando pensamos cada um desses vieses com formas e periodizações, percebemos algo a mais nessa equação, algo que não é explicado, constituindo assim, o entendimento de um elemento desconhecido, de algo ainda não passível de explicação, oculto. A infância, dessa forma, teria uma explicação? Podemos, seguramente, defini-la, conhecê-la?

Dentro dessa perspectiva, de trilhar outros caminhos, propomos construir uma discussão que não só fala sobre a infância, mas que se abre a tudo que ainda nos é desconhecido sobre esta, daquilo que não se pode delimitar. A construção se dá por meio dos dizeres das crianças em torno da infância no ambiente escolar. Partimos de uma perspectiva filosófica que, ao passo que promulga a infância, é por ela explicada (KOHAN, 2007). A infância é, antes de tudo, experiência e seu sujeito um território de passagem.

Enquanto experiência, a infância é "aquilo que 'nos passa', ou que nos toca, ou que nos acontece, e, ao nos passar, nos forma e nos transforma" (LARROSA, 2016, p. 28). A infância 
ensina, de modo particular, a cada passagem, a cada toque, a cada acontecimento e é neste sentido que pensamos e realizamos a pesquisa, como território de passagem para a experiência.

A seguir, expomos a metodologia da pesquisa realizada, destacando desde já, que assumimos o saber da experiência, saber que não se separa do indivíduo concreto em que encarna (LARROSA, 2016) - como pretendeu a ciência moderna, destituindo o caráter inefável do seu preconizado modo de produção de conhecimento.

\section{METODOLOGIA}

Como experiência de iniciação científica, a pesquisa foi realizada com crianças e não sobre crianças, sobretudo por considerar as mesmas como sujeitos sociais capazes de dizer de si e de suas experiências. Partimos de questionamentos acerca do modo como as crianças vivenciam o processo de transição da etapa da Educação Infantil para o $1^{\circ}$ ano dos anos iniciais do Ensino Fundamental.

Nessa direção, dentre os objetivos específicos da pesquisa, que em âmbito geral visou compreender como as crianças enfrentavam o processo de transição da pré-escola para o $1^{\circ}$ ano de escolarização do Ensino Fundamental, está o de analisar os processos de enfrentamento adotados pelas crianças ingressas no $1^{\mathrm{o}}$ ano do Ensino Fundamental.

A metodologia utilizada foi do tipo qualitativa, com enfoque interpretativo na compreensão dos sentidos que existem entre as crianças sobre o contexto escolar. A caracterização qualitativa, segundo Pereira e Cunha (2007), é suporte para o estudo com crianças em virtude da premissa presente nos estudos da subjetividade de que os sujeitos são as suas referências fundamentais, assim como as diferentes formas de organização social e cultural onde se inserem. Dessa forma, se fez necessário considerar aquilo que as crianças têm a dizer sobre suas vidas e sobre o mundo que as cerca.

A pesquisa teve inspiração etnográfica dentro do contexto escolar. Desse modo, foi necessário participar do ambiente que as crianças frequentavam para ouvir o que elas tinham a dizer e ir a esses encontros sem nenhum pressuposto pré-estabelecido que pudesse, de algum modo, coagi-las. Tal como coloca Corsaro (2005), a etnografia é um método utilizado por pesquisadores que se tornam nativos, que integram processo, de modo que, a melhor maneira para que nos tornássemos parte dos universos das crianças foi não agir como adultos típicos.

Revista Interinstitucional Artes de Educar. Rio de Janeiro, V. 6, N.2-pág. 676-691 maio-agosto de 2020: "Bebês e crianças: cultura, linguagem e políticas"

DOI: 10.12957/riae.2020.45962 
Essa visão de Corsaro (2005) foge da visão adultocêntrica e coloca a necessidade de ouvir as crianças, considerá-las quanto às suas opiniões, de colocar-se como sujeitos abertos e livres no entendimento de seus dizeres.

O lócus da pesquisa foi um anexo de uma escola de rede municipal do agreste pernambucano. Especificamente uma sala de aula de $1^{\circ}$ ano do Ensino Fundamental com 16 (dezesseis) crianças, cujas idades eram entre 5 (cinco) e 6 (seis) anos. Destas, apenas 11 (onze) crianças foram autorizadas pelos pais ou responsáveis a participarem da pesquisa, sendo 4 (quatro) meninas e 7 (sete) meninos, cujos nomes, por questões éticas, foram escolhidos em função do quantitativo de crianças participantes da pesquisa ${ }^{1}$. Destacamos que esta escola é a única no município que atende crianças desde a creche até o $1^{\circ}$ ano do Ensino Fundamental.

Nos encontros com as crianças buscamos auxílio da observação participante, do diário de campo e de conversas para além das vivenciadas no dia a dia. Para tanto, em momentos de conversa, foi necessário o auxílio de um gravador de voz, de modo a evitar anotações que pudessem, sobremaneira, descaracterizar o momento junto às crianças, justamente por considerálos como importantes, visto que "a conversa é de alguma maneira e em alguma medida, a arte de se fazer presente, de dar o tempo, isto é, de se colocar disponível a ouvir, a escutar, a pensar e a partilhar com o outro o que nos habita [...]” (SAMPAIO; RIBEIRO; SOUZA, 2018, p. 36).

Na realização desses momentos específicos de conversações junto às crianças, utilizamos uma história no intuito de convocar elementos que agregavam a escola. Em específico, convocamos dimensões como o brincar e o movimento que, de alguma maneira, pudessem mobilizar as conversações e as experiências das crianças quanto à transição que vivenciavam.

Para tanto, elaboramos um pequeno livro com uma história de uma menina chamada Maria, que tinha uma escola repleta de coisas interessantes. A história da escola de Maria retratava o dia a dia dessa criança e de seus colegas na escola, onde todos brincavam, tinham brinquedos e parque ao ar livre, mas, de repente, no curso da história, todas as coisas e cores haviam desaparecido e o assunto era o mesmo desde então entre as crianças: o que aconteceu? Ao longo da história, a professora percebeu o alvoroço das crianças e explicou que a escola recolheu os brinquedos para fazer manutenção e uma reforma. A partir daí o alívio prevaleceu entre as crianças. O nome escolhido para a história foi "A escola de Maria".

\footnotetext{
1 Os nomes das crianças foram substituídos neste trabalho por representações que indicam o quantitativo de crianças que participaram da pesquisa. Desse modo, cada criança é representada por Criança C-1, Criança C-2, [...].
}

Revista Interinstitucional Artes de Educar. Rio de Janeiro, V. 6, N.2-pág. 676-691 maio-agosto de 2020: "Bebês e crianças: cultura, linguagem e politicas" 
A cada encontro com as crianças contávamos a história e, na sequência, realizávamos a conversação. Ao todo foram constituídos três grupos com três crianças e um grupo com duas crianças. Durante a conversação as crianças remetiam-nos às experiências que vivenciavam na escola, bem como às suas percepções quanto àquilo que, diariamente, era oferecido a elas nos espaços e tempos do Ensino Fundamental e que acabavam por influenciar um modo de perceberem a si mesmas e de atuar na escola. Dentre os destaques dados pelas crianças, tratamos aqui, sobretudo, acerca das suas transgressões e criações frente os espaços e tempos da escola.

Seguem seus dizeres e fazeres em meio à infância na escola.

\section{ENCONTROS SILENCIOSOS E POTENTES: O QUE DIZEM E FAZEM AS CRIANÇAS}

No espaço e tempo da escola existem regras e espera-se dos alunos certos comportamentos. Assim as ações das crianças, por vezes, não são consideradas como ideais, mas transgressoras em relação àquilo que se solicita ou espera-se das mesmas. Talvez as atitudes transgressoras das crianças sejam uma forma das mesmas se colocarem como sujeitos que possuem outras vontades e outras singularidades, que não se resumem àquelas ações que lhes são solicitadas. "Obrigadas a participar num "jogo" que a partida não escolheram e/ou desconhecem, elas mostram que são capazes pelas suas próprias razões, de reforçar, modificar, multiplicar, transformar, transgredir e transcender ou simplesmente ocultar aqueles papéis sociais" (FERREIRA, 2002, p. 164-165).

As crianças possuem modos de ver e de interpretar as coisas de forma a pôr suas vontades e seus anseios em evidência. Ferreira (2002) trata acima dos modos como as crianças se portam perante as ações que lhes são solicitadas, destacando que, quando as mesmas não são de interesse das crianças, elas acabam por transgredir e modificar os papéis sociais requeridos. Dentro do contexto escolar, por mais que a instituição afirme a continuidade da pré-escola para o $1^{\circ}$ ano do Ensino Fundamental, haverá diferenças entre estas etapas da Educação Básica e nestas residem as dificuldades e angustias das crianças em incorporar esse outro modo de ser aluno e ser criança.

O agir das crianças tem muito de experiência, pois é a forma particular que cada uma constrói para lidar com a vida e com os desafios que esta propõe. "Todo discurso da experiência 


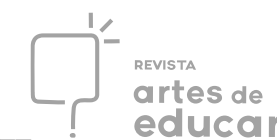

deve partir atualmente da constatação de que ela não é mais algo que ainda nos seja dado a fazer" (AGAMBEM, 2005, p. 21). Aqui o caráter do imprevisto salta aos nossos olhos e aproxima-nos a Larrosa, quando o mesmo afirma que "a experiência não é uma realidade, uma coisa, um fato, não é fácil de definir nem de identificar, não pode ser objetivada, não pode ser produzida" (LARROSA, 2016, p. 10). A experiência acontece. Com ênfase na subjetividade, na sua formação e/ou transformação, ela tem a ver com o acontecimento, com o sujeito da experiência, com o movimento mesmo da experiência (LARROSA, 2011).

Sendo assim, compreendemos que a experiência, por ela mesma, não supõe caminhos organizados e planejados na história, pelo contrário, supõe outras estradas, desconhecidas e cheias de coisas inimagináveis que não dependem da prontidão moderna, mas que se esvaem e adentram por entre as suas brechas. Ela é da ordem do imprevisível, bem como do inefável.

Sendo assim, buscamos atentar às experiências de transgressão das crianças sem, contudo, descrevê-las e/ou explicá-las. Buscamos deixar que elas dissessem e fizessem por si mesmas. Demos-lhes passagem nesta escrita e em nós - o que implicou em uma relação de alteridade, esta que, como Skliar (2014) coloca, é uma condição da experiência, do acontecimento e se dá em meio ao estranhamento, à perturbação, à alteração, ao acaso e ao desconhecimento.

As atitudes das crianças caracterizadas como transgressoras são diversas e cada uma delas são maneiras, por assim dizer, que as mesmas encontram para desenvolver suas vontades. Quando conversamos com as crianças sobre a existência de um lugar proibido na escola, em que as mesmas brincassem, uma menina de 6 anos de idade, depois de pensar rapidamente sobre a questão, fala: "Só aqui nessa sala que não pode. Eu me escondo debaixo da mesa quando venho pra cá pra ninguém me ver" (Criança C-10, em 02/05/2016). A menina falava do lugar em que estávamos naquele momento, uma sala vazia, lugar proibido às brincadeiras, mas não impossível para movimentos de transgressões que permitiam o brincar. Estar naquele espaço, embora reconhecendo os entraves físicos das cadeiras que demarcavam sua entrada, não impedia que houvesse deslocamentos criados pelas crianças para ali estar. As crianças transgridem as regras como meio de se colocar no espaço, partindo de iniciativas que fogem das atitudes consideradas certas pelos adultos. O tempo para as crianças age como intensidade e este não pode ser medido, acusado, julgado.

Revista Interinstitucional Artes de Educar. Rio de Janeiro, V. 6, N.2- pág. 676-691 maio-agosto de 2020: "Bebês e crianças: cultura, linguagem e políticas" 
Temos indícios de dois tempos que se cruzam nesse momento, se interpelam, mas são dicotômicos em sua essência e que diferenciam nosso modo de sentir e de estar no mundo. Remetemo-nos à noção de dois tempos, o chrónos e o aión, ambos percebidos distintamente, mas que existem, simultaneamente, na temporalidade da infância. O primeiro, chrónos, é o mais utilizado, o mais referido, é marcado pela soma do presente do passado e do futuro (KOHAN, 2007). O segundo, aión, é a intensidade do tempo da vida humana, um destino, uma duração, uma temporalidade não-numerável, nem sucessiva, intensiva (LIDDELL; SCOOT, 1966 apud KOHAN, 2007, p. 45). Um construído para medição e outro sentido pelo prazer da experiência, êxtase e vivência atemporal. O tempo aqui equivale mais a língua do prazer do que da pressa (do vai acabar). O tempo que a criança C-10 viveu para se esconder foi um refúgio (o seu), um lugar só dela, onde tudo é possível, sem regras ou fronteiras.

E, nesse caminho, partimos e continuamos a falar de um desconhecido, de potências e de experiências que não carecem de definições, mas promulgam os entre caminhos antes não pensados e que as tornam mais encantadoras, quanto mais misteriosas. Infâncias indo além de explicações, indo em direção de algo desconhecido, do novo, engendrando novas faces, desconhecidas e encantadas, de vidas sem medições, de experiências sem rédeas.

Estamos falando de duas temporalidades, uma soberana, pois rege o curso das coisas, e outra intempestiva, que conduz ao inesperado. Kohan (2007) fala de duas infâncias: uma infância majoritária, de continuidade cronológica e outra minoritária, como experiência e como acontecimento. Ambas não se sobrepõem, elas se encontram constantemente na nossa história. As linhas se tocam, se cruzam, se enredam, se confundem (KOHAN, 2007). A primeira, majoritária segue um curso de etapas, está presente e prevalece nas políticas públicas, nas escolas. Esta, já famosa, é a infância que nós conhecemos e que pensamos como modelo, como regra perfeita a ser seguida. A outra, como resistência, como ruptura e como criação, sua natureza pertence às indefinições e, por isso, não pode ser medida.

A experiência que rege esta última segue um tempo que não precisa de ponteiros, mas de espaço ou de qualquer momento para criação, como efervescência em oposição ao dado. Acreditamos que a experiência inerente à infância minoritária pode realizar, como preconiza Carvalho (2012), um constante fazimento de tudo à sua volta, inclusive da educação, da escola, do currículo, do ensino e aprendizagem.

Revista Interinstitucional Artes de Educar. Rio de Janeiro, V. 6, N.2- pág. 676-691 maio-agosto de 2020: "Bebês e crianças: cultura, linguagem e políticas"

DOI: 10.12957/riae.2020.45962 
Outra situação bastante significativa faz repensar sobre estas transgressões que as crianças desenvolvem e que são formas também de resistir e de criar movimento. Esta refere-se a uma determinada situação registrada no Diário de Campo, na qual a professora deixou-nos com as crianças por "dois minutos", enquanto foi à secretaria da escola, tendo pedido nossa ajuda para observar as crianças em sua ausência. Passados cinco segundos, começaram a surgir pedidos de ida ao banheiro, de idas ao filtro de água, o senta e levanta das carteiras, que cessaram após a chegada da professora.

As atitudes adotadas pelas crianças durante a observação podem ser caracterizadas como os modos de ser e de estar no ambiente, (re)criando outras perspectivas para além daquilo que é oferecido pela escola. Elas instauram a criação na escola, o que Zordan adjetiva de "um voo de vassoura, uma prosa com almas de outro mundo" (ZORDAN, 2010, p. 7). Para a autora, criar não implica em fazer algo novo, mas fazer a diferença.

A forma como as crianças (re)criam o espaço e o tempo escolar da sala de aula observada, a si mesmas e a nós, provoca a diferença na escola. Elas movem a realidade a partir de conversas e ações minuciosas que nos despertam a atenção, seja aos passeios incontáveis para ir ao banheiro e beber água, seja ao brinquedo retirado lentamente da mochila.

Outro ponto observado, também registrado no diário de campo, é a existência das brincadeiras escondidas da professora no momento da aula. Em meio a uma atividade de escrita pelo quadro, uma criança brinca lentamente com dois bonequinhos embaixo da carteira. A tentativa da brincadeira e a esperança de não ser percebida são cessadas pela professora que, ao ver os movimentos, solicita os brinquedos à criança com a justificativa de que sua atitude não é importante naquele momento da aula, pois não era hora de brincar. Quanto a isso, podemos fazer uso das palavras de Kohan:

O intrigante fragmento 52 de Heráclito conecta essa palavra temporal ao poder e à infância. Ele diz que aión é uma criança que brinca (literalmente, "criançando"), seu reino é de uma criança. [...] Esse fragmento parece indicar, entre outras coisas, que o tempo da vida não é questão de movimento numerado e que esse outro modo de ser temporal parece com o que uma criança faz. Se uma lógica temporal segue os números a outra brinca com os números. (KOHAN, 2007, p. 86)

Esse outro tempo é um tempo sem demarcações, sem monitoramento, é um tempo que brinca como uma criança. É um tempo outro, de novas e infinitas possibilidades, um tempo de prazer e alegria de muitos e de poucos, ao mesmo tempo, marcado pelo encantamento que o 
ponteiro de um relógio não traduz. Trata-se de um tempo no qual o passado, o presente e o futuro se confundem, no qual se pode relativizar o próprio tempo, como o faz Larrosa (2016):

Passado. Mínima fração de uma parte da eternidade da qual temos um escasso conhecimento, embora acreditemos que o compreendemos todo. Uma linha em movimento perpétuo chamada Presente o separa de um período imaginário chamado Futuro. (LARROSA, 2016, p. 103)

O modo como as crianças acabam chamando atenção para a dificuldade de incorporar o tempo e o espaço da escola, através de ações consideradas como transgressoras, pode ser caracterizado como a maneira de se posicionarem no ambiente escolar e de realizarem sobre ele as suas vontades e necessidades, brincando com o mesmo, com seu tempo e espaço. Talvez as tentativas de conversas entre as crianças, as brincadeiras escondidas e as incontáveis saídas da sala, sejam maneiras de resistência e enfrentamento que as crianças encontram para se fazerem presentes, para se manterem nesta linha em movimento perpétuo, como bem caracteriza Larrosa (2016).

E, nesta linha, nesses encontros silenciosos e potentes, é importante falar também do novo, da esperança em cada nascimento e da responsabilidade que temos na pretensão de um novo mundo, diferente do que temos, e diverso, um mundo de possibilidades. E, quem sabe, nos atermos ao fato do mundo ser constantemente renovado a cada nascimento, do nascimento irromper em meio à tradição e dar sentido à educação (ARENDT, 2000, p. 223).

Sendo assim, reconhecemos que nossa trajetória educacional junto às crianças pode refletir a possibilidade de um novo rumo, de criação de novas histórias, de experiências, de parceria, de escuta e partilhas múltiplas. No entanto, não poderíamos desconsiderar que, historicamente, a criança, potência da infância, foi e continua sendo silenciada. Nestes termos, enfatizamos que o questionamento proveniente do silenciamento construído e promulgado pelas conjunturas culturais, características de cada sociedade, advém da ausência daquilo que faltou às explicações ou daquilo que não foi possível capturar, estudar, conhecer e elucidar.

Por vezes, esse não conhecer causa espanto, medo e leva-nos ao não exercício do questionamento, ao silenciamento. Ou, por vezes, também nos leva, até mesmo, a querer interromper seus movimentos e potências e os tornar iguais, padrão, conhecidos. Nas palavras de Skliar (2014), a sensação é de que:

Revista Interinstitucional Artes de Educar. Rio de Janeiro, V. 6, N.2-pág. 676-691 maio-agosto de 2020: "Bebês e crianças: cultura, linguagem e políticas"

DOI: 10.12957/riae.2020.45962 
O corpo deve entrar numa determinada ordem - por isso a dupla pressão da propaganda e da medicalização; a atenção deve ser concentrada, fixada - por isso todas as crianças são suspeitas de hiperatividade, de desatenção; a ficção deve acabar e ser reconduzida - por isso a institucionalização, a escolarização; a linguagem deve deixar de trapacear, de fazer metáfora e passar a ser mais sintática - por isso a gramática e a retórica. (SKLIAR, 2014, p. 168)

A partir destes elementos, sobretudo quando nos deparamos com situações de resistências das crianças, percebemos que a infância enquanto potência que não determina e, com isso, não permite a determinação, não vive nesta, mas para além da história de fronteiras, de marcos e de regras; ela convive com as intensidades não numeráveis que habitam nos entre espaços e não carecem de recenseamento, apenas de motivos para transformar o que está posto como regra. Habitam espaços de um devir sempre intenso.

Assim, acreditamos que o movimento que as crianças realizam ao brincar e ao sentir o mundo seria esse tempo, o qual poderíamos chamar de atemporal, marcado pelo sentir e pelo devir. O devir é sempre ordem da aliança (DELEUZE; GUATTARI, 1997), uma ordem outra que não pertence aos rumos que segregam, que estabilizam, que desmistificam. Ele agrega alianças, fios de tempos, de momentos, de instantes que caminham em direção a algo, sem determinações. A criança é constantemente atravessada por tais devires (DELEUZE; GUATTARI, 1997). Um devir que não instaura leis, segue por entre elas. Sendo assim, a ideia de devir criança, que não determina a criança, suas infâncias, flui nos tempos e espaços segundo as particularidades de cada um.

Segundo Kohan (2007, p. 96), “o devir-criança é uma forma de encontro que marca uma linha de fuga a transitar, aberta, intensa". São transitações inesperadas, efềmeras, que marcam essa linha de fuga, esse ser e estar sob o estabelecido, que não comunga com enclausuramentos, mas existe na resistência de criações minúsculas de infâncias, que não se limitam ao dado, ao posto, mas resistem por entre eles. Nas escolas não param esses acontecimentos, ora minúsculos, ora intensos, mas em comunhão com um estado sempre constante da criação.

$\mathrm{E}$ isso tem muito de tempo, da nossa relação não numerável com o tempo. As intensidades que cercam os afazeres diários de todos, e das crianças em especial, comungam com o tempo de uma forma bem diferente da que habituamos a seguir. "É preciso ampliar os horizontes da temporalidade" (KOHAN, 2007, p. 86), entender que esses movimentos contrários 
não caminham com o esperado, respeitar a infância que vai à escola e que reivindica, que quebra as regras, que transgride as normas, que agarra um espaço e um tempo como fuga.

A infância não temporal nunca precisou ser compreendida para ser capturada, nunca se limitou às nossas razões, como também, não se deixa submeter. Aos olhos do poeta Manoel de Barros (2003), a importância de uma coisa não se mede com fita métrica, nem com balanças, nem com barômetros etc., a importância de uma coisa há que ser medida pelo encantamento que a coisa produza em nós. Nesse caminhar entre trilhos, vagarosamente deslumbrante, a infância não permite definições, mas permite ser existência por seu desconhecido encantamento, presente nas coisas minúsculas e sem importância, por nós descomungadas.

Por vezes, as crianças foram silenciadas e, consequentemente, sua infância também, mas existe um caminho, ao avesso é verdade, que, consequentemente ou não, tomou outro sentido. Ora, se existe um silenciamento na infância, esta dura até hoje, pois nada consegue ao certo caracterizá-la com tamanha certeza ao ponto de defini-la. Nesse sentido, ela continua sendo silenciosa, não silenciada, apenas experenciada pelo encantamento produzido em nós, justamente por não a conhecermos. $\mathrm{Na}$ (in)certeza do desconhecimento, seremos eternos encantados pela infância e por tudo mais o que não sabemos, a vida por ela mesma, experenciada.

Conforme aponta o poeta Manoel de Barros (2003), desfazer o normal há de ser uma norma, o imprevisto é mais atraente do que o dejá visto. Neste sentido, Skliar (2003) nos provoca quanto à nossa necessidade diária de definir o outro a partir da mesmidade, daquilo que estamos ou fomos acostumados a lidar e a considerar como padrão. Somos constantemente levados a pensar o outro como mais um. Somos, com isso, levados a caracterizar e a criticar o outro como aquele que é, que foi, que será, sem nos questionarmos sobre "o estar sendo".

A infância é o outro que nossos olhos tentam ou tentaram reduzir a uma lógica puramente racional e notadamente pensada. No entanto, dentro da perspectiva aqui exposta, a infância não é, não foi, nem será, ela está sendo. Assim, não conseguiremos defini-la, ela está em movimento contínuo, é nômade, é presente. Não cabe a ninguém fixar a mesma. Ela não cabe em definições, nem em formas dadas a pensar.

\section{CONSIDERAÇÕES FINAIS}


A infância e a criança são, insistentemente, pensadas a partir de critérios definidos e baseados em lógicas enrijecidas, como a biológica, a partir dos quais se fixam limites, como os cronológicos. Este enrijecimento está presente e é compartilhado em nossas instituições educativas, desde as de Educação Infantil. Ele sintetiza uma infância que parece ser passível de limites, porém, a infância que adentra nesses espaços e tempos é outra, resistente, questionadora, afirmativa, criativa, transgressora. Com isso, ela provoca-nos, faz-nos igualmente outros, resistentes, questionadores, afirmativos, criativos e transgressores, sobretudo, na escola.

O discurso das três metamorfoses do espírito, presente no livro "Assim falou Zaratustra", de Friedrich Nietzsche (2003), mostra como um camelo passa a um leão e de leão à criança. O Camelo seria a carga pesada, os fardos, a submissão que, ao ir para o deserto, se transformou em leão, pois renunciou ao "sim", agora imponente diz "não", porém sem conseguir transformar as coisas segundo sua vontade. Para este último feito, ele teria que mudar para criança, pois, para Nietzsche (2003), a criança é como a inocência e o esquecimento, como um novo começar, um brinquedo, uma roda que gira sobre si, um movimento, uma santa afirmação.

O estado de criança seria essa forma leve e suave de lidar com as situações que não dependem do que está posto como regra a ser seguida e, com isso, de transformar e criar, de ser outra coisa, diferente, sem forma. A criança resiste e, com isso, flui em devires que atravessam o tempo e intensificam sua experiência, sem etapas, sem números e sem demarcações. Sendo importante notar o quanto as instituições que atendem crianças estão cheias desses movimentos, minúsculos, transformadores.

Diante de tudo isso, é importante salientar que é imprescindível que se multipliquem olhares sensíveis à condição da infância, da sua particularidade, que não precisa ser medida, nem qualificada, tampouco comparada e/ou classificada. São os espaços de liberdade que as compõem, que provocam a criação, momentos de pura experiência. Além de tudo, precisamos semear meios de escuta e olhar mais aguçados e portadores de respeito quanto a tudo que as crianças têm a nos dizer e a nos mostrar. Meios cúmplices da experiência da infância, meios, sobretudo, capazes de construir pontes que ligam, que partilham a (r)existência.

\section{REFERÊNCIAS}

Revista Interinstitucional Artes de Educar. Rio de Janeiro, V. 6, N.2- pág. 676-691 maio-agosto de 2020: "Bebês e crianças: cultura, linguagem e políticas"

DOI: 10.12957/riae.2020.45962 
AGAMBEN, G. Infância e História: destruição da experiência e origem da história. Belo Horizonte: UFMG/Humanitas, 2005.

ARENDT, H.. Entre o passado e o futuro. Trad. Mauro W. B. de Almeida. 5a . ed. São Paulo: Editora Perspectiva, 2000.

ARIÈS, P. História social da criança e da família. $2^{\circ}$ ed. Rio de Janeiro: Guanabara,1983.

BARROS, M. de. Memórias Inventadas. A infância. São Paulo, Editora Planeta do Brasil: 2003.

CARVALHO, J. M. (Des)território currículo, aprendizagem e infância: deslizamentos antidogmáticos do aprenderensinar. 2012. Encontro Nacional de Didática e Práticas de Ensino. XVI, 2012, Campinas. Anais Eletrônicos... Disponível em:<

http://www.infoteca.inf.br/endipe/smarty/templates/arquivos_template/upload_arquivos/acervo/d ocs/1275b.pdf > Acesso em: 22 jan. 2018.

CORSARO, W. A Entrada no campo, aceitação e natureza da participação nos estudos etnográficos com crianças pequenas. Educ. Soc. [online]. 2005, vol.26, n.91, pp.443-464. Disponível em: <http://www.scielo.br/pdf/es/v26n91/a08v2691.pdf.> Acesso em: 03 jan. 2016.

DELEUZE, G.; GUATTARI, F. Mil Platôs. Capitalismo e esquizofrenia. Vol. 4. tradução de Suely Rolnik. São Paulo: Editora 54, 1997.

FERREIRA, M. "A gente aqui o que gosta mais é de brincar com os outros meninos!": as crianças como atores sociais e a (re)organização social do grupo de pares no cotidiano de um Jardim de Infância. 2002. 646f. Tese (Doutorado em Ciências da Educação) - Universidade do Porto, Porto, 2002.

KOHAN, W. O. Infância, estrangeiridade e ignorância. Belo Horizonte: Autêntica, 2007.

KRAMER, S. A infância e sua singularidade. In: BEAUCHAMP, J.; PAGEL, S. D.;

NASCIMENTO, A. R. (orgs). Ensino Fundamental de nove anos: orientações para a inclusão da criança de seis anos de idade. Brasília: Ministério da Educação, Secretaria de Educação Básica, 2007, p. 13-23.

LARROSA, J.. Tremores: Escritos sobre experiência. Tradução Cristina Antunes, João Wanderley Geraldi. Belo Horizonte: Autêntica Editora, 2016.

Experiência e alteridade em educação. Reflexão e Ação - Revista do Departamento de Educação e do Programa de Pós-graduação em Educação. v. 19, n. 2, 2011. Disponível em:<https://online.unisc.br/seer/index.php/reflex/article/view/2444/1898> Acesso em: 05 dez. 2016.

MORENO, G. L.; PASCHOAL, J. D. A Criança de Seis Anos no Ensino Fundamental: Considerações Iniciais. In: BRANDÃO, C. da F.; PASCHOAL, J. D. (orgs.). Ensino

Fundamental de Nove Anos: teoria e prática na sala de aula. São Paulo: Avercamp, 2009.

Revista Interinstitucional Artes de Educar. Rio de Janeiro, V. 6, N.2-pág. 676-691 maio-agosto de 2020: "Bebês e crianças: cultura, linguagem e políticas" 
NIETZSCHE, F. Assim falou Zaratustra. São Paulo: Editora Martin Claret, 2003. (Coleção A obra-prima de cada autor, v. 22).

OLIVEIRA, Z. R. de. Educação Infantil: Fundamentos e Métodos. São Paulo: Cortez, 2008.

PEREIRA, R. S.; CUNHA, M. D. A pesquisa na escola com crianças pequenas: desafios e possibilidades. APRENDER - Cad. de Filosofia e Psic. da Educação Vitória da Conquista Ano V n. 8 p. 113-130, 2007.Disponível em: http:

$</ /$ periodicos.uesb.br/index.php/aprender/article/viewFile/4069/pdf_179>. Acesso em: 10 out. 2015.

POSTMAN, N. O desaparecimento da infância. Rio de Janeiro: Graphia, 1999.

RIBEIRO, T.; SOUZA, R. de; SAMPAIO, C. S. Conversa como metodologia de pesquisa: Uma metodologia menor. In: Conversa como Metodologia de pesquisa: por que não? Rio de Janeiro: Ayvu, 2018.

SKLIAR, C.. Pedagogia (improvável) da diferença: e se o outro não estivesse aí? Tradução Giane Lessa. Rio de Janeiro: DP\&A, 2003.

Desobedecer a linguagem: educar. Tradução Giane Lessa. Balo Horizonte: Autêntica Editora, 2014.

ZORDAN, P.. Arte com Nietszche e Deleuze. Revista Educação e Realidade. v. 30, n.2, p. 261- 272, jul./dez., 2005.

\footnotetext{
${ }^{\text {i }}$ Mestre em Educação Contemporânea (Universidade Federal de Pernambuco), Email: nadiapri1@hotmail.com Brejo da Madre de Deus/PE, ORCID: https://orcid.org/0000-0002-8088-5341

ii Mestre em Educação Contemporânea (Universidade Federal de Pernambuco), Email: fernanda.m.s.albuquerque@ gmail.com Caruaru/PE, ORCID: https://orcid.org/0000-0003-1852-9247

iii Doutora em Educação (Universidade Federal de Pernambuco). Professora Associada I da UFPE, Centro Acadêmico do Agreste, Professora do PPGEduc (Programa de Pós- Graduação em Educação Contemporânea) da UFPE/CAA. E-mail: cgislane@terra.com.br Caruaru/PE, ORCID: https://orcid.org/0000-0003-3930-512X
}

Revista Interinstitucional Artes de Educar. Rio de Janeiro, V. 6, N.2- pág. 676-691 maio-agosto de 2020: "Bebês e crianças: cultura, linguagem e políticas" 